


\section{A essência da televisão aberta contemporânea}

The essence of contemporary broadcast television

\section{Cárlida Emerim ${ }^{1}$}

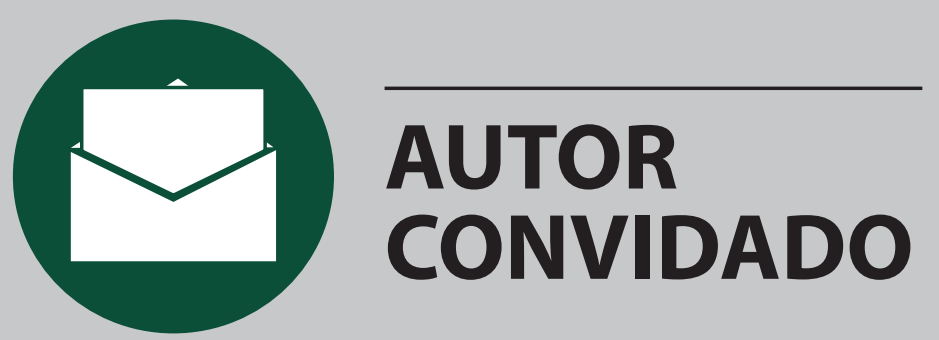

PORTO ALEGRE | v. 19 | n. 31 | 2014 | pp. 12-19

Sessões do Imaginário

\section{Resumo}

Partindo da crença de que a televisão aberta tem um longo e produtivo caminho no mundo futuro, o presente artigo propõe refletir olugar de pertencimento da televisão na sociedade brasileira comoobjetivo de analisar o impacto da convergência, da produção colaborativa e da proposta interatividade da audiência (público telespectador) nos produtos midiáticos televisivos. Tal reflexão se fundamenta em proposições de autores advindos dos Estudos Culturais que analisam a modernidade articulados com a proposição analítica sobre a mídia inspirada na Semiótica Discursiva.

\section{Palavras-chave}

Televisão, convergência, produção colaborativa, telespectador, inovação

\section{Abstract}

Starting from the belief that broadcast television has a long and productive way in the future world, this article proposes to reflect the place of belonging of television in Brazilian society with the goal of analyzing the impact of convergence, collaborative production and the interactivity of the audience (public viewer) proposed in television media products. This reflection is based on authors of Cultural Studies that analyze modernity articulated with the Semiotics Discourse analytic proposition about media.

\section{Keywords}

Television, convergence,collaborative production, viewer, innovation 


\section{Para um começo de conversa}

Repercute, nos últimos anos, nas mais diferentes áreas, a prospecção sobre o esgotamento do modelo de televisão aberta no Brasil. Alguns, mais radicais, afirmam o fim da própria televisão. Porém, mesmo diante de tantas críticas e diagnósticos negativos, a televisão aberta brasileira ainda é o veículo de massa mais popular e mantém o seu poder como o maiorícone da era das imagens e da informação. Dados recentes de pesquisas divulgadas pelo Instituto Brasileiro de Opinião, Pesquisa e Estatística (IBOPE), divisão Ibope Media $^{2}$ e pelo Instituto Brasileiro de Geografia e Estatística (IBGE) 3 , estimam que 95,1\% das residências do país possuam aparelhos de televisão, alcançando um total de mais de 155 milhões de televisores ${ }^{4}$.

Os resultados também apontam crescimento em todos os setores, pois o brasileiro assiste, em média, cerca de 5 horas e meia de televisão por dia. Entre os telespectadores, quem mais está assistindo televisão são as faixas etárias com mais de 50 anos e a de 4 a 11 anos - respectivamente, 42 minutos e 38 minutos a mais de consumo diário que os dados de pesquisas anteriores (2008 e 2012). Em outro aspecto, a pesquisa também mostra que a televisão é o único meio de acesso à informação e ao entretenimento para mais de $49 \%$ da população brasileira e que, nas periferias das grandes cidades, os aparelhos de televisão permanecem ligados durante os finais de semana, por mais de 15 horas.

Diante do contexto descrito, por que, então, a televisão aberta brasileira vem sendo alvo de tão acirradas críticas? A perspectiva deste artigo é a de refletir sobre esta questão com o objetivo de mostrar o poder e a importância da televisão aberta na sociedade brasileira partindo do ponto de vista histórico e tecnológico. É intuito, também, compreender as perspectivas destas críticas e suscitar percepções sobre a permanência da televisão aberta como um meio imprescindível à sociedade contemporânea e futura.

Para tanto, recorre aos teóricos dos Estudos Culturais, que compreendem não só as práticas como os usos das mídias, articulados com os pressupostos da Semiótica Discursiva, que analisa os objetos a partir de suas especificidades e efeitos de sentido. A estrutura do artigo inicia com uma contextualização histórica sobre a televisão e as mensagens televisivas e segue, discutindo o tema, entremeando as proposições da articulação teórica empreendida.

\section{Entre sedução e tecnologia: os percursos da mídia TV}

Se recorrermos a um olhar, do ponto de vista mais histórico, pode-se afirmar que, desde o surgimento da televisão, as mensagens midiáticas foram ganhando novas formas, mais rápidas e eficientes, de transmissão. Um contexto que repercutiu diretamente no aumento do poder persuasivo da TV. A "caixa preta", como foi "apelidada" no início, ganhou status na vida dos cidadãos e, com os avanços tecnológicos, um poder de penetração e força inegáveis, capazes de influenciar os parâmetros sociais. Foi a televisão analógica que construiu este percurso que se efetivou pelo tipo de tecnologia por ela apresentada.

A palavra televisão deriva de tela de visão, ou seja, de uma tela de superfície de armazenamento eletrostática de um tubo de raios catódicos na qual a informação é visualmente apresentada. Era, pois, o dispositivo utilizado para a exibição de dados num terminal - o vídeo. Esta tela da televisão, seguindo a gênese da imagem em movimento transformouse num espaço de apresentação da realidade, pois o imediatismo de sua reprodução técnica lhe concedia o status de recorte do real, função reforçada pela possibilidade de exibição ao vivo dos fatos e, também, pelos cenários específicos que reproduziam as cenas da vida cotidiana. Mesmo que simuladamente, este real aproximado pela televisão transformou as telas, rapidamente, no espelho da alma contemporânea. As imagens, as produções audiovisuais, as produções televisivas, são uma espécie de catalisadores do inconsciente, que possibilitam a interpretação, a tradução e o reconhecimento, de parte do telespectador, nas telas, daquilo que são os desejos mais secretos, a voz interior. Por isso, essas imagens televisivas conseguiram emaranhar-se com um número tão grande de diferentes telespectadores e alcançaram esse poder de persuasão e identificação com idades e classes sociais distintas.

O suporte técnico do sistema televisivo foi o vídeo, que, por suas características eletrônicas, conferiu à mídia televisiva uma compreensão própria, ou seja, um tipo específico de leitura de imagem. Por leitura de imagem, entende-se a capacidade do olhar de compreender e apreender os significados de determinada manifestação imagética (Emerim, 2000, p. 32).

Outro fator a ser lembrado é a importância da imagem no universo midiático: para a mídia televisiva a imagem é o principal instrumento de repercussão e utilização dos seus processos 
comunicacionais e paradigmas. A imagem apresentase como possibilidade de abstração, pois o campo do audiovisual move-se na área do quase - quase real, quase verdade -, tornando-se a realização tecnosocial de uma aparência (Sodré, 2000).

Naturalmente, segundo Arnheim (1998), há distinções entre as imagens captadas diretamente pelo olho humano e aquelas que são mediadas pelas máquinas, antes de serem captadas pelos nossos olhos. As que se vêem diretamente são escolhidas pelo espectador e enquadradas de acordo com sua vontade. Aquelas apresentadas pela máquina através do vídeo, cinema e fotografia - não permitem ao espectador escolha, já feita pelo olho da máquina, que opera como mediadora. As imagens provocam atitudes, opiniões, reações ou percepções individuais, visto que a experiência de cada um é solitária individual e única. Pode até se tratar de experiências compartilhadas, e quase sempre o são, mas na mente, no inconsciente, no banco de dados da memória de cada um, vão ser registradas de forma que só aquele indivíduo poderá acessar.

Mas, se essas experiências são individuais, existe algo que se transfere para o outro: a significação. Essa significação, esses sentidos são o que se tornam públicos, o espaço onde a sociedade torna visível os seus valores, representações, ações, políticas, práticas, etc. É sobre esses sentidos que construímos as experiências imagéticas, as quais, por sua vez, se tornam condutoras de produção de sentidos que se refletem por todos os outros campos. As imagens são potencialmente fontes de poder pela manipulação das aparências e é na televisão, ou seja, na mídia televisiva, que esses paradigmas são exaustivamente utilizados e se refletem diretamente na questão do código televisivo e na experiência televisual.

A mídia televisiva sempre se estruturou sob uma imagem que não se referenda no real, partindo dos truques, das montagens, da possibilidade de manipular as coisas do mundo, além de ter, na essência, uma mutabilidade constante do pixel em movimento. $E$ os telespectadores acabam consumindo a realidade audiovisual como se fosse a realidade "real". Essas características são essenciais à compreensão do processo de expressão televisivo, pois é no espaço determinado pela tela que se dá a representação da realidade. Uma realidade que a mídia televisiva transformou em entretenimento, como se o mundo cotidiano, a vida real, fosse matériaprima à espera de ser processada, transformada em programas de televisão. A agilidade na transmissão dos fatos simultaneamente ao seu acontecimento e a plasticidade que a iguala ao cinema fez da televisão o veículo ideal de propagação de notícias que, nesse contexto, tornam-se tão divertidas quanto os filmes de ficção (Emerim, 2012).

A experiência televisiva constituiu um fator importante de entendimento das relações existentes entre o indivíduo e o contexto social no qual ele está inserido. Qualquer ser humano que assistia à televisão aberta ficava em contato com inúmeros contextos e situações que só podiam ser vistos pela televisão. Sobre este modelo, Thompson (1998) explica que a televisão produzia "[...] um contínuo entrelaçamento de diferentes formas de experiência, uma mistura que torna o dia-a-dia de muitos indivíduos hoje bastante diferente do experimentado por gerações anteriores" (p. 54). Os cidadãos se encontravam ligados às coisas

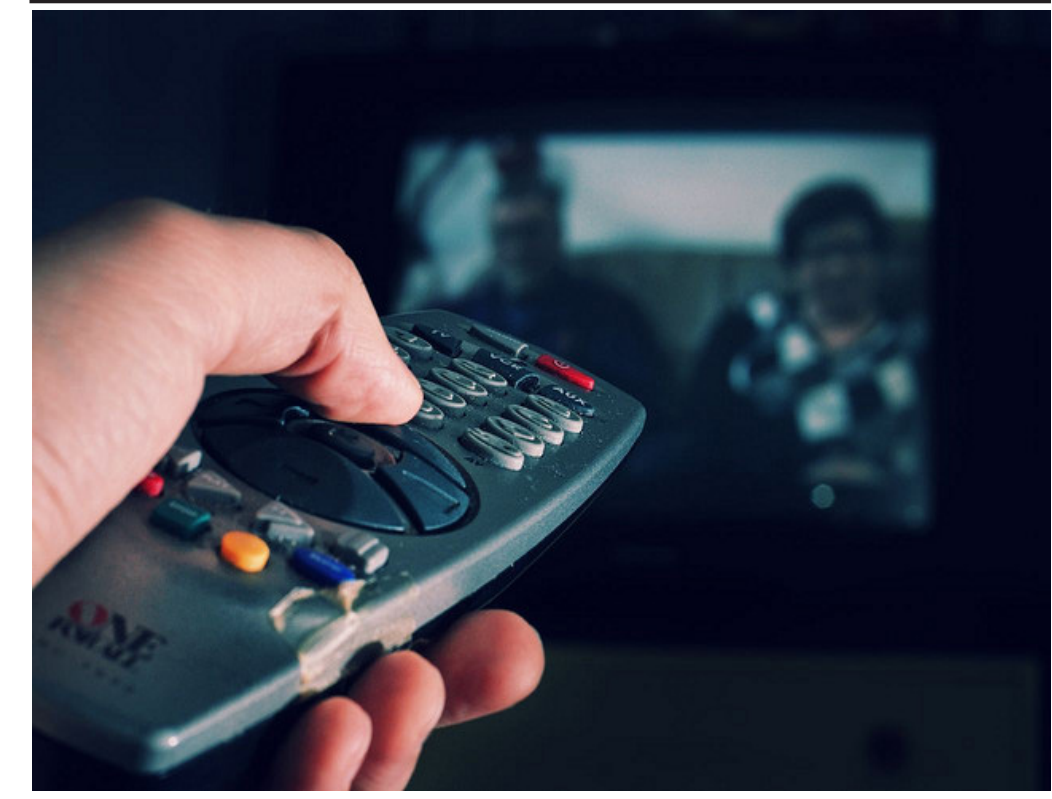

do mundo a todo instante, bastando para isso ligar ou desligar o aparelho de televisão. Ou seja, mesmo antes da internet, a televisão aberta já permitia, em instâncias mais indiciais, uma espécie de experiência de conectividade e convergência trazida pelo que se pode denominar de perpétuo presente da enunciação televisiva. Alguns estudiosos, como Arlindo Machado (1997) e Beatriz Sarlo (1996), creditam esse poder às inúmeras horas que os telespectadores passavam frente à televisão, no mundo inteiro. Machado diz:

A televisão penetrou tão profundamente na vida política das nações, espetacularizou de tal forma o corpo social, que nada mais the pode ser "exterior", pois tudo o que acontece de alguma forma pressupõe a sua mediação, acontece, portanto, para a TV (Machado, 1997, p.08). 
Com tal poder, pressupôs-se que nada poderia ficar fora dos alcances eletrônicos, pois a televisão engendrou a sensação de que toda a realidade estaria sob o domínio do telespectador, no interior da sua casa, através da tela. É essa ideia de acesso total a toda e qualquer faceta da realidade que lhe permitiu apresentar-se como espetáculo. Um espetáculo exibido essencialmente ao vivo, em direto, em que as noções de transmissão e emissão são reconfiguradas, produzindo um discurso no qual o tempo do relato tende a ser confundido com o tempo da enunciação e com o tempo dos fatos narrados. Ao trazer os fatos do mundo para a intimidade, para o interior das casas dos cidadãos, como se eles ali acontecessem, a televisão aberta criou um espaço específico de vivência, de passagem entre o exterior e o interior $\mathrm{e}$, ao mesmo tempo, derrubou a fronteira entre o público e o particular/privado.

Nessa perspectiva, a televisão aberta consolidouse como mediadora no processo comunicativo, ficando entre os dois polos: o telespectador e os fatos do mundo. Porém, trabalhou o tempo inteiro com o apagamento dessa fronteira, tentou e conseguiu ser invisível, imperceptível, utilizando diferentes estratégias - como a estratégia do 'ao vivo" ou da simulação do "ao vivo" -, enfatizando a ideia de que a vida, os fatos do mundo, todos estão ou podem estar na tela da televisão. Um resultado de sentido importante desta estratégia, que também fortaleceu a relação de pertencimento da televisão aberta na vida da sociedade brasileira, é o estatuto de companhia da modernidade. A televisão ligada nas casas das pessoas tornou-se o outro que, mesmo não estando presente fisicamente, tornava-se presente pela tela televisiva.

\section{Mediação e linguagem televisiva: a} aproximação com o telespectador

É impossível pensar numa mídia televisiva alheia aos anseios sociais, assim como uma sociedade que não se identifique nesse universo midiático. Através desse processo de mediação, a mídia televisiva construiu uma aproximação com o telespectador, uma interação tão poderosa que ultrapassou, de muito, suas próprias expectativas. As imagens do mundo, impostas, a cada dia, aos nossos olhos, pela mídia, acabavam fazendo parte de nossa experiência individual como se fossem diretas e não mediadas, como o são realmente. E é exatamente por esta característica que seu poder de penetração ainda é maior do que o de qualquer outro meio de massa da atualidade.

A vida social é orientada por símbolos, entendidos como signos que indicam valores aos seres sociais, fazendoparteesignificandoemum determinadoespaço, contexto, situação. É assim também com a cultura, a ciência, a religião, a política, segmentos constituintes da sociedade e que, de certa forma, oferecem pistas do que vai se constituir no fazer midiático. Para alguns autores tais como Harry Pross (1980), Jesus MartínBarbero (1997) e Fredric Jameson (2007), a televisão sempre obteve um poder maior de inserção, porque suas narrativas imagéticas despertam a imaginação dos telespectadores quando eles se encontram mais frágeis e desprevenidos. Ou seja, quando estão no seu tempo livre, em casa, confortavelmente instalados em suas salas ou quartos diante da televisão e, portanto, mais sujeitos a uma sucessão de ofertas de modelos e desejos, geralmente evasivos e curtos, mas completamente adequados a esse ambiente.
No aspecto da linguagem televisiva, ou nos modos de como ela construiu seus próprios textos, pode-se afirmar que, com o desenvolvimento das novas tecnologias, que tornaram possível uma maior participação do telespectador nesses processos televisivos, abriu-se também o leque de exigências fundado na fala comum. Essa fala comum, antes restrita ao repertório ou conteúdo dos programas e comerciais, passou a incorporar também a própria linguagem televisiva. É o que René Berger (1977) classificaria como microtelevisão, aquela formada por grupos restritos que têm interesses comuns e manipulam os recursos técnicos portáteis de vídeo e, ampliando o que propõe o autor, também de televisão digital5, produzindo programas direcionados a circuitos fechados. Este fator, aliado à globalização, fundou um paradigma que valoriza o local como fonte de identificação, potencializou a ideia de que falando com a aldeia se fala com o mundo.

Diz Caetano Veloso6 que "[...] o sol se reparte em crimes, espaçonaves, guerrilhas, em Cardinalles bonitas, eu vou [...] em caras de presidentes, em grandes beijos de amor, em dentes, pernas, bandeiras, bombas e Brigite Bardot". A fragmentação da programação em programas, a segmentação dos programas em blocos, entremeados por intervalos comerciais, fizeram o texto televisivo diferente estruturalmente de outros textos. E, ainda, se aliarmos a esse diferencial o zapping como um processo inerente ao fazer videovisivo ou televisivo, pode-se considerar o telespectador também como elemento produtor nessa construção.

Zappear é pular sem paradeiro de um canal para outro, ver quase que simultaneamente um pouco de noticiário e de um filme romântico e de um comercial 
e, assim, infinitamente. Zappear, às vezes, está para além da consciência: é um ato desinteressado, mas totalmente contaminado de atitudes televisivas.

Mas, para zappear, é preciso utilizar do controle remoto, um aparelhinho que, quando surgiu, era um produto de elite. Só o possuía quem estivesse disposto a pagar cerca de $25 \%$ a mais pelo aparelho de televisão, pois não eram todas as marcas ou modelos que traziam consigo esta facilidade tecnológica. Entretanto, como vários outros produtos industrializados, hoje, qualquer televisão possui o controle remoto que oferece inúmeros recursos, tais como controle de voz de trilhas sonoras e mesmo da possibilidade de ver, na mesma tela, através de janelas abertas - pois, são efetivamente telas de computador -, vários canais ao mesmo tempo.

Num artigo publicado em 1987, Cora Rónai e Márcia Cezimbra7 afirmavam que o controle remoto foi a coisa mais aproximada, em nossa época, da varinha de condão, desde que as fadas haviam sido varridas dos livros e colocadas para dentro da tela da televisão. O controle remoto substituiu o poder mágico de trocar de cena; com o controle remoto nas mãos, o telespectador passou a ter o poder de escolha, de decisão sobre o canal e a programação e, consequentemente, foi inserindo seus valores, necessidades e desejos nesta forma sutil de manipulação.

Já na televisão aberta analógica, o controle remoto possibilitava que o cidadão estabelecesse, por meio de gravação em horários diversos, a sua própria programação, retirando, das inúmeras ofertas, somente aquelas que mais Ihe interessavam. Com o controle remoto, os chamados usuários comuns puderam passar a ter o controle sobre a televisão aberta na forma de escolha da programação e passaram a ser, numa primeira instância, o que Toffler (1980) definiu como "consumidor produtor", ou seja, o prosumer $\mathrm{E}$, ao fazerem essas escolhas, acabaram construindo novas montagens do próprio texto televisivo. O telespectador foi ensinado pelos meios audiovisuais a seguir certas regras de construção dessas escolhas e passou a ter, no controle remoto, seu instrumento primordial. Para Sarlo (1996), o zapping manteve o interesse dos telespectadores na televisão, pois lhes permitiu uma espécie de montagem caseira delineada pelo desejo de mudar de canal, concedendo-lhes a autoridade de dominar (ou não) o desejo à frente da mão que faz pulsar o controle remoto.

Dessa forma, com o controle remoto e sua utilização facilitada, veio também uma nova postura dos telespectadores: ver simultaneamente o que está acontecendo em outros canais ou de repartir a tela em imagens diferentes, como se fossem mosaicos coloridos interrompidos por cortes ou chuviscos.

Ocorre que, com o zapping, o telespectador não viu mais programas inteiros, mas, sim, uma televisão de mudanças contínuas de canais, uma fragmentação desordenada cujo resultado, como um todo, parecia ao de um quebra-cabeça. É possível assistir, ou melhor, dividir a assistência entre os programas favoritos apresentados simultaneamente em canais diferentes. Entre um comercial e outro, existe um tempo infindável de trocas e manipulações que o espectador utilizava com satisfação de "dono" de sua vontade; o controle remoto é uma base de poder simbólico que é exercido segundo leis que a televisão ensinou aos seus espectadores, como bem aponta Sarlo (1996. p. 57). E, é neste aspecto que a televisão aberta começou a enfrentar alguns de seus grandes desafios contemporâneos. Se não, vejam.

$\mathrm{Se}$, por um lado, o telespectador, com o controle remoto na mão, mudava constantemente de canal, em busca da programação que mais lhe agradasse, de outro, tornou-se difícil medir a audiência dos programas, o que influenciou a comercialização e a própria configuração dos produtos midiáticos. A escolha da programação e dos produtos a serem veiculados pelas emissoras passou a ter que considerar cuidadosamente esse novo hábito do receptor e levou ao desenvolvimento de uma série de estratégias a serem empregadas na construção desses programas televisivos.

A possibilidade do zapping quebrou totalmente com a audiência inercial, ou seja, com a "preguiça" de trocar de canal e a adoção de um canal preferencial. Essa espécie de salto incessante acabou construindo novas narrativas, amarradas pelos cortes dos telespectadores nas imagens que são montadas para serem apresentadas. Criou-se, com isso, uma nova estética, baseada na mixagem, na bricolagem, na velocidade e no desenvolvimento tecnológico das mídias modernas.

Apropriando-se disso, a televisão aberta passou a se utilizar da fala comum como estratégia de aproximação e, consequentemente, de captação de um número maior de receptores, construindo, através de sua programação, uma espécie de mixagem: toda a sua fala passou a ser comum direcionada a todos e a um só indivíduo, ao mesmo tempo. Um procedimento referendado pela popularização dos processos eletrônicos e pelo acesso aos equipamentos portáteis que propiciaram uma certa liberdade de expressão 
provinda das massas: qualquer um podia ter uma câmera de vídeo e flagrar imagens da realidade e transmiti-las em circuito fechado ou aberto ou, até mesmo, enviá-las às emissoras de televisão que transmitissem esses acontecimentos captados em espaços onde as câmeras profissionais não estavam presentes. Na atualidade, as câmeras de celular fazem este papel e a internet eliminou o envio de materiais para as emissoras, excluindo, consequentemente, o lugar de mediação da televisão aberta para a exibição e produções dos "amadores".

Esta fala comum imagética reforça os efeitos de presença da realidade e enfatiza o efeito de ausência de mediador entre os fatos do mundo e os cidadãos, sendo um elemento crucial na caracterização desse novo contexto: os textos televisivos agregam à fala comum a expressão de videomakers ou mobilemaker incorporando-a ao fazer profissional. Esse formato, hoje, se assemelha ainda mais ao real, ao que se vê pelas ruas, como se os olhos "limpos" do povo fossem mais reais, mais verdadeiros do que os olhos cheios de

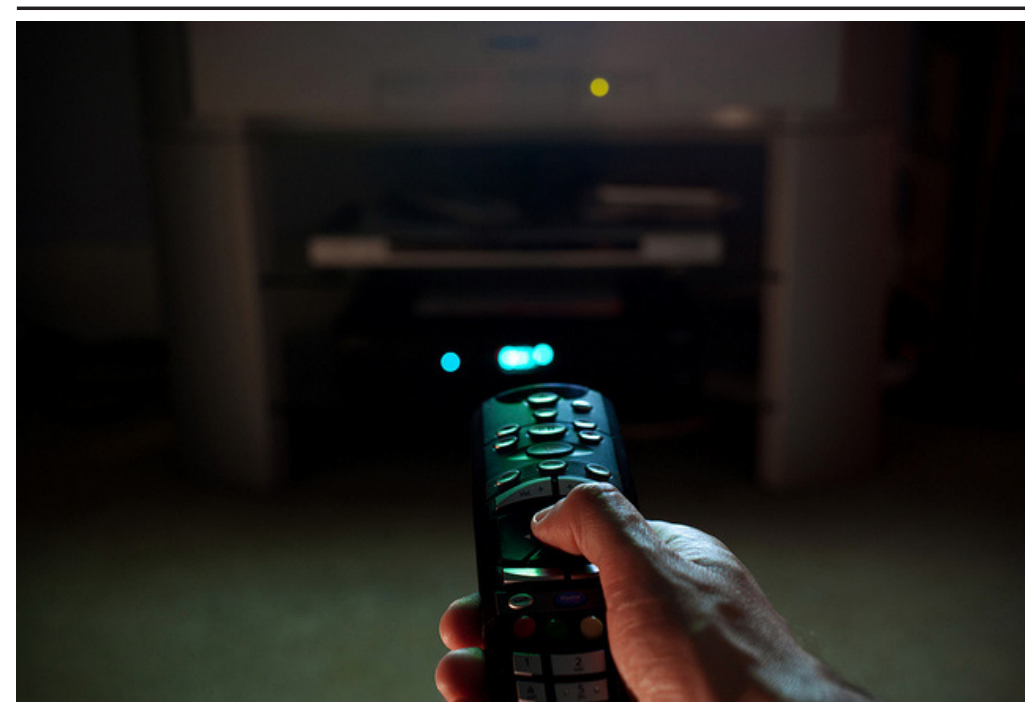

truques do que é mostrado pelas televisões abertas convencionais, tão cheias de regras e leis do que podem ou não exibir em suas telas.

Mas a tevêaberta,queparecenão inovar, incorporou este fazer em seu processo produtivo, materializando esta oxigenação que vem deste mercado exterior ao seu e, ao mesmo tempo, se beneficia com a produção de vanguarda e dos produtores independentes ligados a formas mais alternativas de trabalho como também passa a deter o controle sobre estas produções. $O$ reflexo desse processo pode ser visto, ainda hoje, nas programações de televisão aberta e mesmo nas televisões a cabo, pela apropriação de formatos diferenciados em seus programas, pela adoção de recursos retóricos que quebram as regras do fazer televisivo tradicional.

\section{Convergência, produção colaborativa e audiência}

A mídia televisiva e os programas de televisão, em seus diversos estilos ou padrões, sempre repetiram determinadas estruturas não só para construir uma caracterização, uma identidade junto ao público mas, também, para responder a uma acepção de que, ao saber o que "vai ver na televisão", o telespectador mantém-se fidelizado, porque esse saber the confere uma certa estabilidade, tranquilidade (Barbero,1997). Com essa concepção padronizada, durante muito tempo a televisão conseguiu "estabilizar" um certo número cativo de audiência, ou seja, buscou caminhos de identificação com o público consumidor desses estilos; porém, na contemporaneidade, essa audiência, cada vez mais, tem se tornado um público estética e culturalmente mutável.
Porém, nos últimos tempos, a concorrência com a internet e sua promessa de liberdade total de exposição de imagens e dados, sem controle legal ou moral, tem implicado num repensar obrigatório sobre as produções televisivas. Frente a esta conectividade e intermediação descentralizada, os telespectadores têm se mostrado, cada dia, mais voláteis, sem estabelecer relações de fidelidade a um canal, produto ou programa. Inversamente proporcional ao emprego de tecnologias diferenciadas em cenários, transmissão digital e número de equipamentos, os telespectadores parecem mais insatisfeitos com a programação da televisão aberta.

As pesquisas que vem sendo desenvolvidas8 sobre o "gosto do telespectador televisivo" ofertam algumas pistas. Entre elas pode-se citar que a produção da televisão aberta: 1) está produzindo conteúdos defasados da realidade de um público que tem um acesso "irrestrito" via uma comunicação horizontal, a internet e as redes sociais - não se supera o imediatismo destes modelos e plataformas; 2) mudaram e cresceram as expectativas deste público/receptor/consumidor e produtor (pois, com a popularização da digitalização de dados passou a ter acesso facilitado a equipamentos portáteis de gravação e transmissão, em alta qualidade) e recebe surpreendentes e constantes inovações através das redes sociais, geralmente, de forma gratuita; 3 ) muito recentemente passou a preocupar-se, efetivamente com o público telespectador, quer seja para produzir de forma direcionada ou para potencializar as características diferenciais da televisão aberta para visar a um público distinto. É impossível pensar numa audiência convergente sem que se pense na

17 PORTO ALEGRE | v. 19 | n. 31 | 2014 | pp. 12-19 Sessões do Imaginário 
estrutura produtiva da televisão aberta e, em que medida ela pode, realmente, se fazer convergente e potencializar as narrativas informativas com qualidade e compromisso com o público.

Em outra direção, no que se refere à linguagem essencialmente televisiva, o mais importante é a programação ao vivo e o investimento numa fala comum para as grandes audiências. Essa é a essência da televisão aberta contemporânea e, em verdade, o foi sempre, só que a televisão e seus produtores esqueceram-se disso. O desafio é o de compreender que, com a migração e a popularização da TV na Internet, tem-se mais possibilidades de experimentar novas linguagens e o melhor exemplo disso está em sites como o YouTube, no qual o público é totalmente responsável pela produção e a divulgação do conteúdo disponibilizado.

Diante desse mercado de convergência e de uma audiência extremamente fragmentada e, por consequência, de difícil aferição, é imprescindível propor formatos de produtos e modelos de produção que sejam ágeis, que possam inovar $e$ surpreender o público de forma contínua, não apenas diante de novas (e infindáveis) crises de mercado. Uma estratégia interessante seria empregar uma observação permanentemente sobre o que se produz e o como se produz, objetivando a entrega de conteúdo de qualidade dentro desta perspectiva de hipersegmentação9. Mas, para isso, é fulcral uma mudança de postura e de visão mercadológica dos gestores de emissoras de televisão aberta, que possam de fato gerar propostas mais inovadoras.

Ao final, depois de se empreender esse percurso sobre a perspectiva histórica e tecnológica da televisão aberta brasileira pode-se depreender que ela é presente e importante para a sociedade brasileira e que suas mudanças estéticas estão intimamente ligadas às exigências dos movimentos mercadológicos mas, fundamentalmente, às mudanças e permanências advindas do público consumidor. Pode-se afirmar também, que não é a nova tecnologia ou o fato de o telespectador ser alçado a produtor colaborativo que mais impacta na televisão atual, mas sim a falta de uma produção de conteúdo que possa efetivamente refletir o que de melhor a televisão aberta tem a ofertar aos seus telespectadores.

A fidelização e a colaboração da audiência podem ser potencializadas pela convergência de processos produtivos, utilizar o que a convergência define (confluência, encontro, junção) para aproximar (o telespectador prosumer) e qualificar a produção televisiva. Nessa direção, também, pela concepção de grade de programação, que ela oferte produtos em multiformatos, cuja padronização esteja muito mais na qualidade de formas narrativas diferenciadas, no ato de contar boas histórias com criatividade.

Por último, porém, talvez, o mais importante, produzir e pensar numa produção que tenha a perspectiva permanente em conhecer e produzir para o telespectador que efetivamente assista à televisão aberta brasileira; um telespectador que esteja contemplado no texto televisivo, que possa participar das produções como colaborador e que, finalmente, veja na televisão aberta um espaço de produção de conteúdo interessante para o seu dia a dia, para a sua rotina de vida em sociedade. Isto é possível, com certeza. Desde que os produtores de televisão compreendam o real significado da palavra convergência e passem a permitir a experimentação criativa livre com a participação conjunta do público de televisão, o telespectador que é, de fato e de direito, o objetivo de qualquer emissão televisiva em canal aberto.

\section{Referências}

ARNHEIM, Rudolf. Arte e percepção visual. São Paulo: Thomson Pioneira, 1998.

BARBERO, Jesús Martin. Dos meios às mediações Comunicação, cultura e hegemonia. Rio de Janeiro: Editora UFRJ, 1997.

BERGER, René. Arte e Comunicação. São Paulo: Edições Paulinas, 1977.

EMERIM, Cárlida; BRASIL, Antonio. Hipersegmentação: pensando o conceito de telejornal na convergência. Anais do $1^{\circ}$ Encontro Nacional de Pesquisadores em Jornalismo (SBPJor). Brasília, Universidade de Brasília, 2013.

EMERIM, Cárlida. As entrevistas na notícia de televisão. Florianópolis: Insular, 2012.

Muvuca: ensaios sobre o texto televisivo. Dissertação de Mestrado. Programa de PósGraduação em Comunicação da Universidade do Vale do Rio dos Sinos, defendida em 2000.

JAMESON, Frederic. Pós-Modernismo: a lógica cultural do capitalismo tardio. São Paulo: Ática, 2007.

MACHADO, Arlindo. A Arte do Vídeo. São Paulo: Brasiliense, 1997. 
PROSS, Harry. La violencia de los símbolos sociales. Barcelona: Antrophos, 1980

RONÁl, Cora; CEZIMBRA, Márcia. Controle remoto A televisão sob medida. Folha de São Paulo, 1987, Caderno de Cultura.

SARLO, Beatriz. Cenas da vida pós-moderna. Rio de Janeiro: Ed. UFRJ, 1996.

SODRÉ, Muniz. Colóquio sobre o "Ethos Midiático". UNISINOS (RS), Março de 2000.

THOMPSON, John P. A Mídia e a Modernidade. Petrópolis: Vozes, 1998.

TOFFLER, Alvin. A Terceira Onda. Rio de Janeiro: Record, 1980.

\section{Notas}

1 Doutora em Ciências da Comunicação (UNISINOS). Professora do Programa de PósGraduação em Jornalismo da Universidade Federal de Santa Catarina (UFSC - Campus Trindade - CCE - Bloco A - Departamento de Jornalismo - CEP: 88040-970). E-mail: carlidaemerim@gmail.com.

2 Publicada pelo IBOPE Media, disponível em $<$ http://www.ibope.com.br/pt-br/noticias/Paginas/Ainternet-e-a-principal-fonte-de-entretenimento-para43-dos-jovens-aponta-IBOPE-Media.aspx>. Acesso em 16 jul. 2014.
3

Dados disponíveis em <http://ultimosegundo. ig.com.br/brasil/2012-04-27/ibge-pela-1-vezdomicilios-brasileiros-tem-mais-tv-e-geladeira-d. html>. Acesso em 28 abr. 2012.

4 Dados disponíveis em < http://memoria. ebc.com.br/agenciabrasil/noticia/2011-04-19/ pesquisa-mostra-que-brasil-tem-85-milhoes-decomputadores-em-uso>. Acesso em 26 abr. 2014.

5 Aliás, cabe ressaltar que René Berger, em 1977, classifica as emissões em três categorias baseado na experiência televisual: macrotelevisão - televisões voltadas para as grandes massas (estatais ou comerciais); a mesotelevisão - televisões a cabo e locais e a microtelevisão - grupos restritos de interesses comuns em circuitos fechados. Na época de escrita de Berger o vídeo era o sistema mais avançado, portanto, incluiu-se aqui a televisão digital por acreditar que se a tecnologia fosse disponível naquele tempo ela estaria incluída na definição do autor.

6 Na letra da música Alegria, Alegria, escrita por Caetano Veloso, inclusa no álbum Caetano Veloso, da Universal Music, lançado em 1968.

7 Publicado originalmente no jornal Folha de São Paulo.

8 O Grupo Interinstitucional de Pesquisa em Telejornalismo (GIPTele), sediado no Departamento de Jornalismo da UFSC, vem desenvolvendo pesquisas que se preocupam com a análise da produção televisiva, a proposta de conteúdos para os novos modelos de televisão bem como a configuração do telespectador.

9 No SBPJor de 2013, o termo foi apresentado pela autora (em texto conjunto com pesquisador Antonio Brasil) para compreender esta nova modalidade produtiva do telejornalismo em relação ao público contemporâneo o qual, aqui, pode também ser empregado para a produção televisiva mais geral. 